\title{
Measuring regional differences in users' perceptions towards interurban toll roads
}

\author{
Juan Gomez, Anestis Papanikolaou, José Manuel Vassallo
}

Keywords:

Regional differences

Users' attitudes

users' perceptions

Toll road

Multilevel model

Spain

\begin{abstract}
A B S T R A C T
Public acceptability is crucial to achieve the successful implementation of certain policy initiatives. In the transport sector, this is especially relevant for toll roads since they entail a burden to the users. Previous literature in this field has mainly focused on analyzing the influence of different individual characteristics on attitudes towards road charges, without clear results. However, other context-specific drivers such as regional parameters may also play an important role to explain users' attitudes, especially when the implementation of tolls within the same nation varies throughout regions. The goal of this paper is to analyze regional differences in users' perceptions with regard to tolls as an appropriate way to finance the provision of road infrastructure. Based on a nationwide survey conducted to road users in interurban toll roads in Spain, we develop a multilevel logit model to explore regional differences in drivers' perceptions. The research concludes that differences identified seem to be more influenced by context-specific variables, related to either the characteristics of the toll road or the region, than by the characteristics of the individuals. The paper also underlines the negative effects of an asymmetrical distribution of toll roads across regions on users' perceptions, since those territories especially suffering the burden of tolls show a more negative attitude towards road charging.
\end{abstract}

\section{Introduction}

Public acceptability has traditionally been identified as one of the key drivers to achieve a successful implementation of different policy initiatives (Marciano et al., 2014; Aitken et al., 2014). Regarding the transport sector, this is especially relevant in the case of road charging strategies (Zheng et al., 2014; Kockelman et al., 2009), that is being a policy increasingly adopted by governments to collect stable resources to face budgetary constraints. In this respect, Dill and Weinstein (2007) claim that policy makers must seek to recommend options that not only have strong public support, but are also desirable in terms of equity, ability to generate stable revenue, capacity to encourage environmentally responsible choices, etc.

Despite the increasing literature on attitudes towards tolls and acceptability of road user charges, there is a need for a more comprehensive approach (Kallbekken et al., 2013). The existing literature has traditionally analyzed the influence of individual characteristics (age, income, trip purpose, etc.) on perceptions towards toll roads, leading to inconclusive results (Gehlert et al., 2011). By contrast, no previous efforts have been made to include explanatory variables at the regional level or specifically address regional differences on toll road acceptability. This approach may be crucial when road charging characteristics greatly vary across regions within the same nation.

Spain constitutes an interesting case in the international context to explore regional differences on users' attitudes towards toll roads. While the current Spanish high capacity road network is one of the longest ones within Europe, it is made up of both tolled and free roads asymmetrically distributed across regions. As pointed out by Vassallo et al. (2012), this is due to the changes over time of the road transport policy implemented by different governments. As a result, while some regions such as Catalonia or Valencia have a dense toll motorway network, the percentage of free high capacity roads is significantly higher in other areas of the country. As pointed out by Gomez et al. (2015), this heterogeneity has provoked negative sentiments towards road charging in certain regions along with political complaints. In fact, protest groups and associations have recently appeared in some regions of Spain (such as Catalonia) to coordinate actions against tolls because of the sentiment of unfairness perceived when compared to the rest of Spaniards.

The aim of this paper is to analyze regional differences in users' perceptions towards financing the provision of roads through toll mechanisms, given an asymmetrical distribution of toll infrastructure 
facilities across regions. Based on a nationwide survey conducted in interurban toll roads, we develop a multilevel logit model to measure the influence of individual, road-related and regional variables in users' perceptions.

This paper is organized as follows. After this introductory chapter, Section 2 summarizes the state of knowledge on perceptions towards road charges and identifies some research gaps in the literature. Section 3 describes the data collected from a survey conducted to road users and the explanatory variables included in this research. Section 4 outlines the multilevel methodology adopted to explore regional differences in drivers' attitudes, and Section 5 presents and discusses the results. Finally, Section 6 shows the main conclusions and points out further research.

\section{Literature review}

Previous studies on attitudes towards road charging have been mainly focused on urban contexts, with special attention to the implementation of congestion charging systems in city centers (Furst and Dieplinger, 2014; Schuitema et al., 2010; Gaunt et al., 2007). By contrast, the literature analyzing perceptions on interurban areas is still limited and primarily concerns residents' perceptions rather than users' (Kockelman et al., 2009; Dill and Weinstein, 2007).

Till now, research efforts have been mainly directed towards measuring the influence of individual socioeconomic factors (age, gender, income, etc.) on road pricing attitudes. These studies-potentially useful to target specific user market segments-have not generally led to conclusive and coincident results about the influence of these types of variables on attitudes as noted by Yusuf et al. (2014) and Odeck and Kjerkreit (2010). Because of this lack of evidence, some authors (Schade and Schlag, 2000; Rienstra et al., 1999) have pointed out that socioeconomic factors might have a somewhat lesser impact on acceptability than other drivers such as attitudinal factors.

The study of the acceptability of toll road pricing constitutes a complex issue that can be approached from different perspectives (Zheng et al., 2014) such as the perceived fairness of charges (Cools et al., 2011; Fujii et al., 2004), political bias (Hårsman and Quigley, 2010) or existing community values (Yusuf et al., 2014). Particularly, Smirti et al. (2007) acknowledged that the level of acceptability may sometimes be highly context-specific, so attitudes may change across roads or, at an upper level, even across territories with different characteristics. Despite the fact that the literature admits this problem, as of today, little effort has been made to incorporate the regional perspective in the acceptability analysis, or to measure regional differences on users' perceptions towards road charging.

There are some research studies dealing with regional differences in certain transport modes such as air transport (Alberts et al., 2009) or maritime (Castillo-Manzano and Fageda, 2014; Oosterhaven et al., 2001). However regional differences have scarcely been addressed for road transport issues, and when analyzed they have been limited to specific areas such as road safety (Tolon-Becerra et al., 2013; Eksler et al., 2008; Lassarre and Thomas, 2005), or spillover indicators (CondeçoMelhorado et al., 2011). The papers by Sandow (2008) and Abane (2011) are among the few studies in the literature incorporating the geographic perspective in the analysis of travelers' behavior.

Regarding acceptability towards road charging, some research studies made a preliminary approach to regional differences. Podgorski and Kockelman (2006) analyzed public support for toll roads in Texas, and found that those regions with small urban areas were more receptive to road charging. According to the authors, this result may be influenced by the fact that residents could be thinking of tolls not applied to roads in their areas. Also focusing on Texas, Kockelman et al. (2009) identified a higher support in those regions having past positive experiences with toll roads. In the same line, the study by Dill and Weinstein (2007) in California pointed out that regional experience with toll facilities appeared to increase support for tolling.
Despite the interest of these findings regarding road charging acceptability, there is still room for a different types of analysis that models users' instead of residents' perception. In addition, when focusing on regional differences, it is possible to use hierarchy in the survey data to properly address differences among respondents and therefore avoid the so-called may "atomistic fallacy" (see more comments in Section 4), present in some of the researches previously mentioned.

To sum up, some research gaps can be identified concerning the current state of knowledge in this topic. First, further explanatory variables than individual characteristics-such as regional parameters or tolling infrastructure attributes-need to be addressed to have a more thorough picture. Second, the existing literature has not specifically focused on users' attitudes but on public perceptions in general. And third, we are not aware of any previous research mainly focusing on regional differences on users' perceptions towards toll roads that use specific modeling techniques for this purpose.

\section{The data: a nationwide survey in Spanish toll roads}

In order to measure users' perceptions towards interurban toll roads and explore potential differences across regions, we develop a multilevel binary logit analysis. To that end, we collected data from a nationwide survey (see Appendix 1) developed in several Spanish interurban toll roads in 2010 . With the aim to identify potential regional differences not in public acceptability but in drivers' perceptions, the questionnaire was specifically addressed to users of interurban toll roads. It was conducted between October and November, 7-days a week in order to get a representative sample in terms of users' trip purpose, since its distribution generally vary during the week. The data was collected from personal interviews at service areas or petrol stations near the existing tolling infrastructure. We stratified the sample in order to achieve sufficient representativeness at the regional level.

As this paper is mainly focused on identifying regional differences in users' attitudes, the network covered in the survey includes the Spanish regions with a toll road network homogeneously distributed over the territory. The network surveyed combines regions with mature toll roads, where user charging was implemented decades ago, along with regions with a more recent toll network. Catalonia, Madrid, Valencia, the Basque Country and Galicia were the cases ultimately selected for this research. Other potential regions (Andalusia, Castilla-La Mancha, Castilla y León) were not included in the end because toll roads are located only in specific areas of the region. This may result in users' perceptions towards tolls widely varying over the same region, making the analysis more difficult.

Then, the network ultimately surveyed comprises all the interurban toll roads starting and/or ending in the 5 regions selected. The sample includes respondents selected in a balanced way from the regions chosen (see Appendix 2). The data size is large enough to be considered representative for each region. In total, 2769 users from 30 toll roads were surveyed. The resulting sample, made up by $2264 \mathrm{~km}$, can be also considered representative of the Spanish toll network, as it includes around $75 \%$ of total tolled $\mathrm{km}$ in the country. We would like to note that it is among the longest interurban toll road systems ever surveyed in the literature.

The data was collected through face-to-face questionnaires especially designed for research purposes. In order to capture respondents' attitudes towards toll roads, the questionnaire requested them to report whether they considered tolls as an appropriate way to finance the provision of road infrastructure. This is an approach previously adopted to measure respondents' road charging acceptability such as in Odeck and Brathen (2008). Their answers at this point are the dependent variable to be modeled through the multilevel logit specification detailed below.

In order to model users' perceptions on toll roads, three levels of explanatory variables were included in this research (see Table 1). Firstly, individual characteristics-the first level of data-were collected 
Table 1

Description of variables included in the research.

\begin{tabular}{|c|c|c|c|c|}
\hline \multicolumn{2}{|l|}{ Variable } & Subgroup & \multirow[t]{2}{*}{ Respondents } & \multirow[t]{2}{*}{ \% Sample } \\
\hline \multicolumn{3}{|l|}{ Dependent variable } & & \\
\hline & & Positive & 1451 & 52.4 \\
\hline \multicolumn{2}{|c|}{ User perception towards toll roads } & \multirow[t]{2}{*}{ Negative } & \multirow[t]{2}{*}{1318} & \multirow[t]{2}{*}{47.6} \\
\hline Explanatory variables & & & & \\
\hline \multirow[t]{25}{*}{ Individual characteristics } & \multirow[t]{2}{*}{ Gender } & Male (base reference) & 1454 & 52.5 \\
\hline & & Female & 1315 & 47.5 \\
\hline & \multirow[t]{5}{*}{ Age } & Under 24 (base reference) & 148 & 5.3 \\
\hline & & From 24 to 34 & 453 & 16.4 \\
\hline & & From 35 to 49 & 1153 & 41.6 \\
\hline & & From 50 to 64 & 773 & 27.9 \\
\hline & & Above 64 & 242 & 8.7 \\
\hline & \multirow[t]{5}{*}{ Type of vehicle } & Car (base reference) & 2452 & 88.6 \\
\hline & & Light van & 201 & 7.3 \\
\hline & & Truck & 96 & 3.5 \\
\hline & & Moto & 9 & 0.3 \\
\hline & & Bus & 11 & 0.4 \\
\hline & \multirow[t]{5}{*}{ Income } & Under 20,000 Euro (base reference) & 725 & 26.2 \\
\hline & & From 20,000 to 30,000 Euro & 926 & 33.4 \\
\hline & & From 30,000 to 50,000 Euro & 394 & 14.2 \\
\hline & & Above 50,000 Euro & 95 & 3.4 \\
\hline & & Not responding & 629 & 22.7 \\
\hline & \multirow[t]{2}{*}{ Frequency/type of user } & Frequent (base reference) & 2099 & 75.8 \\
\hline & & Occasional & 670 & 24.2 \\
\hline & \multirow[t]{6}{*}{ Trip purpose } & Commuting (base reference) & 845 & 30.5 \\
\hline & & Business & 331 & 12.0 \\
\hline & & Weekend leisure & 744 & 26.9 \\
\hline & & Holiday leisure & 534 & 19.3 \\
\hline & & Other & 315 & 11.4 \\
\hline & & & Toll roads & $\%$ \\
\hline \multirow[t]{5}{*}{ Infrastructure characteristics } & \multirow[t]{2}{*}{ Quality of the alternative route } & Conventional road (base reference) & 22 & 74.2 \\
\hline & & Highway & 8 & 25.8 \\
\hline & Unitary toll rate & (Euro/km) & Mean: 0.13 & Sd: 0.09 \\
\hline & \multirow[t]{2}{*}{ Type of toll infrastructure } & Road (base reference) & 26 & 87.1 \\
\hline & & Tunnel & 4 & 12.9 \\
\hline \multirow[t]{4}{*}{ Regional parameters } & GDP per capita & (1000 Euro/person) & Mean: 25.87 & Sd: 5.07 \\
\hline & Political beliefs & $\%$ votes for left-wing parties & Mean: 46.3 & Sd: 3.6 \\
\hline & Nationalist/regionalist feelings & $\%$ votes for nationalist/regionalist parties & Mean: 27.3 & Sd: 25.8 \\
\hline & Abundance of toll roads & $\%$ high capacity $\mathrm{km}$ being tolled & Mean: 32.1 & Sd: 12.8 \\
\hline
\end{tabular}

through personal interviews. Secondly, we incorporated a set of explanatory variables regarding the attributes of tolling infrastructure. This represents the second level in the model. Finally, a group of regional parameters made up the third level of data. As can be seen, although the main objective of the research was to identify potential regional differences on users' perceptions, the inclusion of an intermediate level concerning the characteristics of the toll infrastructure was necessary to properly take into account the existing hierarchy in the data. In this respect, potential heterogeneity may appear in users' perceptions among toll roads, given some differences observed in terms of physical or charging attributes.

Individual characteristics of users, as well as attitudes towards toll roads, were collected through face-to-face questionnaires (see details in Appendix 1). In the first part, drivers were asked about their socioeconomic and transport-related characteristics (age, level of income, type of vehicle used, trip purpose, etc.), generally grouped into different categories as shown in Table 1. Among further explanatory variables potentially determining individuals' perceptions towards tolls, the political beliefs can be identified as a relevant one. However, due to the objection frequently shown by respondents to report ideological concerns in some regions of Spain, the current research approached this issue at the regional level by analyzing the political atmosphere of each region.

The second level of data in the model was made up of infrastructure attributes, including physical and charging characteristics with regard to the toll road used. Although it is acknowledged that the level of acceptability towards road pricing may be highly context-specific (Smirti et al., 2007), the characteristics of the tolling infrastructure have not been explicitly incorporated as explanatory variables in previous modeling approaches. They are expected to have a significant influence on users' attitudes, and also to be useful to explain potential differences among users of different types of toll roads.

Among the road infrastructure variables, we firstly included the quality of the free parallel road available in each case, since it increases the possibility for users to skip tolls and therefore might be a significant explanatory factor to determine users' perceptions. It is important to note that in Spain it is a requirement that every toll concession has a free parallel road available in the same corridor. The binary variable adopted distinguishes between toll roads whose free alternative route is a conventional (two-lane) road, generally with poor quality, and those ones competing with high capacity roads (highways). Additionally, we included the toll rate per kilometer charged in each road as an explanatory variable, in order to capture the potential effect of the charging level on users' perceptions. This parameter was collected from the Spanish Ministry of Transportation database (Ministerio de Fomento, 2011a). Finally, a binary variable was considered to differentiate between purely interurban toll roads and tolled point sections (tunnels).

Finally, the third level of data is made up of a set of independent variables at the regional level in order to explain potential differences in users' attitudes across regions. Firstly, GDP per capita-expressed in 1000 Euro/person-intends to capture the influence of the average standard of living within each region on toll road acceptability, in a similar way as other papers measuring public acceptability (Karlsdotter et al., 2009). Moreover, an explanatory variable referring to the abundance of toll roads in each region is inserted in the model. This variable is 
measured as the percentage of high capacity road km being tolled within each particular region, according to the Spanish Ministry of Transportation database (Ministerio de Fomento, 2011b). The regions considered in the research show significant variability at this point given that a great proportion of the high capacity network is tolled in regions such as Catalonia (47.2\%) or the Basque Country (41.2\%), while this percentage is much lower in other regions such as Madrid (14.9\%). In that respect, we may expect that those regions with a higher presence - in relative terms - of toll roads might show a more negative attitude.

Political beliefs have also been identified as a driver potentially influencing perceptions towards road charging (Hårsman and Quigley, 2010). We approach the effect of the political atmosphere in each region by considering the general support obtained by either right- or leftwing parties. Notwithstanding the fact that a complementarity with data at the individual level would have been highly desirable, analyzing the effect of the political climate on users' perceptions remains a relevant issue given the key role played by the regional governments of Spain in social and economic beliefs. Specifically, we included the percentage of votes obtained by left-wing parties in the last regional elections in the country. We may expect that the political climate may be less supportive of tolls in regions governed by socialist/communist parties, while a higher presence of conservative parties would favor more positive attitudes towards toll roads. In addition, we include an explanatory variable concerning the support for nationalist/regionalist parties (those parties supporting more independence from the central government or even full independence) within each region, with the aim to measure the influence of nationalist feelings on general attitudes towards tolls. The reason behind that is the great opposition against tolls by nationalist parties in certain regions such as Catalonia.

Table 1 summarizes the main characteristics of the data sample. A balanced proportion of men and women were surveyed, with a higher presence of people aged between 35 and 49 (41.6\%). Furthermore, we observe users' income typically lying below Euro 30,000, and a vast majority of cars (88.6\%) regarding the type of vehicle used. The high share of respondents $(22.7 \%)$ not reporting their income is also noticeable. Commuting (30.5\%) and weekend leisure (26.9\%) are the most common trip purposes in the sample, with a high proportion of respondents (75.8\%) making $>8$ trips per month (frequent users).

Concerning toll infrastructure, a significant percentage of the sample drives in interurban toll roads competing with conventional roads. It can be noted that, for the network surveyed, there is a great asymmetry across regions regarding the alternative to the toll road (see Appendix 2 ). Tolled sections competing with free highways are numerous in regions such as Madrid, while in the Basque Country or Catalonia the alternative route is generally made up of a conventional (two-lane) road. Some variability is also found in other explanatory variables such as the toll rate applied, nationalist/regionalist feelings or abundance of toll roads across regions. Finally, we would like to note the balanced proportion of respondents in the sample from the 5 regions surveyed: Catalonia (20.1\%), Valencia (20.3\%), Madrid (19.8\%) the Basque Country (20.1\%), and Galicia (19.6\%). The sample reached a data size large enough to be representative of toll road users in each territory. Further details about the survey conducted to collect the data for this research can be found in Gomez et al. (2015).

\section{Methodology}

In order to measure users' perceptions towards interurban toll roads and explore potential differences across regions, we develop a multilevel binary logit model. This type of specification represents an extension of the classical regression models, in the sense that they take into account potential correlation between data observations due to hierarchical or nested structures in the data.

When hierarchically/nested structured data are present in the sample, classical regression models become not valid since the assumption of independent observations is violated (Koppelman and Bhat, 2006).
In this case, we can expect that observations belonging to the same group may share common characteristics while being also different from other existing groups. Failing to account for these differences may lead to the so-called "atomistic fallacy", with important negative consequences in the results. Firstly, a misinterpretation of estimates is commonly associated, since inferences regarding variability across groups are drawn based on the individual level of data (Hox, 2002). Secondly, it may lead to spurious statistical significances of parameter estimates in the model, due to an underestimation of the standard errors calculated. As underlined by Goldstein (2003), these limitations can be overcome by using multilevel (or hierarchical) models, since they recognize the existence of such data hierarchies.

Based on a more complex structure, multilevel specifications consider a different model for each level of data. This also allows exploring inter-group variability at different levels. Among other advantages, these models make possible not only to quantify the relationship between variables within the same level, but also to estimate their influence on other levels defined in the data.

For our research, we apply the standard multilevel approach, based on random coefficients, that has been widely described in the literature (de Leeuw and Meijer, 2007). In order to model users' acceptability towards toll roads, this technique is combined with a logit specification given the binary nature of the dependent variable (see Section 3). Particularly, we model the probability that respondents consider tolls as an appropriate mechanism to finance the provision of roads.

Binary choice models fall into the category of utility maximization models, assuming that a person chooses the alternative with the higher utility (Ben-Akiva and Lerman, 1995; Train, 2003) among all the options available. The utility of each choice $\left(U_{i k}\right)$ is a random variable that can be determined by a number of explanatory parameters $\mathrm{X}_{\mathrm{p}}$. The binomial logit approach developed in this research follows the standard procedure so for further detail the reader is referred to Gujarati and Porter (2004); Koppelman and Bhat (2006) or Train (2003).

Simultaneously, the model accounts for the hierarchical level of the data by adopting the multilevel technique. The data needed for the research were collected from different toll roads, which can be subsequently grouped into regions (see an illustrative example in Fig. 1; the specific application to the case study selected is included in Appendix 3 ). Therefore, the modeling framework was assigned a three-level structure $(\mathrm{i}-\mathrm{j}-\mathrm{k})$. Subscript $\mathrm{i}$ is related to individuals, while $\mathrm{j}$ and $\mathrm{k}$ refer to the toll road and regional level, respectively. As in every multilevel approach, higher levels of the hierarchy (toll roads and regions) are considered themselves a sample from a general population of toll roads and regions.

The model comprises random effects at both intercepts and slope parameters, allowing random variations among toll roads $(\mathrm{j})$ and regions $(\mathrm{k})$, as shown below in a general form:

$Y_{i j k}^{*}=\beta_{0(n) j k}+\beta_{1(n) j k} X_{1 i j k}+\ldots+\beta_{p(n) j k} X_{p i j k}+\varepsilon_{i j k}$
$\beta_{0(n) j k}=\beta_{0(n)}+u_{j k}+u_{k} ; \quad \beta_{p(n) j k}=\beta_{p(n)}+u_{j k}+u_{k}$

where $\beta_{0(n) j k}$ is the model intercept, consisting of a fixed intercept $\beta_{0(n)}$, a random variation $\mathrm{u}_{\mathrm{jk}}$ of this intercept across toll roads and a random variation $\mathrm{u}_{\mathrm{k}}$ of this intercept across regions, in a similar way as in Papadimitriou et al. (2014). Then, it allows intercepts to vary randomly at each different level (toll roads and regions). In a similar way, $\beta_{1(n) j k}$ is the coefficient for explanatory variable $X_{1}$, also allowing variability across toll roads $(j)$ and regions $(k)$. Finally, $\varepsilon_{i j k}$ is the common idiosyncratic error. Therefore, it is possible to structure the total variation in the model into three different error terms:

$E_{i j k}=u_{k}+u_{j k}+\varepsilon_{i j k}$

where random variations defined above are independently distributed: $\mathrm{u}_{\mathrm{k}} \sim \mathrm{N}\left(0, \gamma^{2}\right) ; \mathrm{u}_{\mathrm{jk}} \sim \mathrm{N}\left(0, \tau^{2}\right) ; \varepsilon_{\mathrm{ijk}} \sim \mathrm{N}\left(0, \sigma^{2}\right)$. In this respect, a significant random intercept with regard to regions (toll roads) indicates that 


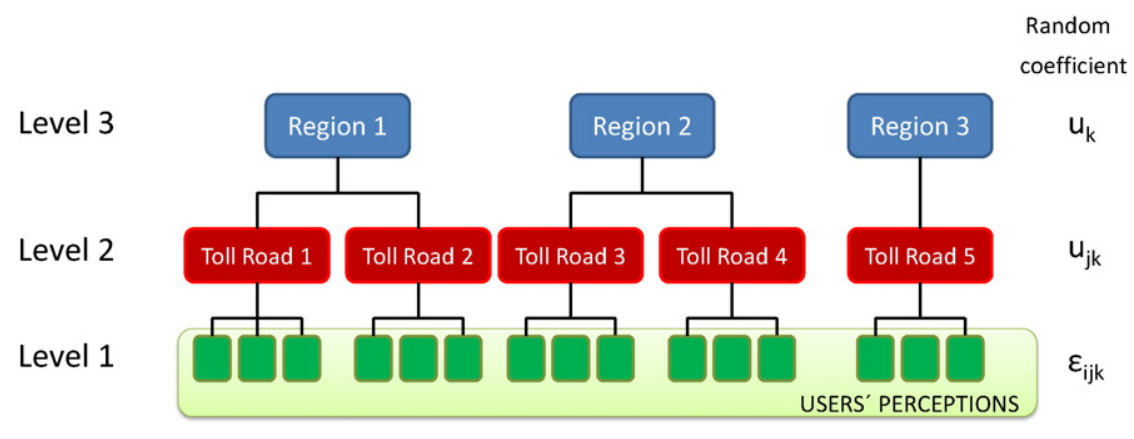

Fig. 1. Hierarchy in users' perceptions considered in the multilevel model adopted: illustrative example.

divergences between responses are due to unobserved regional (toll road) differences, and not to differences across respondents. Additionally, a significant random slope with regard to regions (toll roads) means that the influence of a certain explanatory variable $\mathrm{X}_{\mathrm{p}}$ does significantly vary across regions (toll roads).

The explanatory variables in the model comprise individual characteristics $\left(\mathrm{X}_{\mathrm{ijk}}\right)$, toll road attributes $\left(\mathrm{X}_{\mathrm{jk}}\right)$ and regional parameters $\left(\mathrm{X}_{\mathrm{k}}\right)$, as it was explained more deeply in Section 3. Given the different level of the independent variables, the hierarchical analysis followed the traditional stepwise procedure, developed in greater detail by Murillo (2008), among others. Through this method, subsequent models are generated by gradually incorporating the explanatory variables into the analysis:

- Model 0: only including intercepts and random effects (no explanatory variables).

- Model I: incorporating individual characteristics to the model.

- Model II: adding toll road attributes to the analysis.

- Model III: including regional parameters in the model.

Throughout this process, the model repeatedly evaluates the improvement in the fitting of the model that is achieved due to the gradual inclusion of new explanatory variables. Along with this, the methodology makes possible to check the statistical significance of the random effects included, in both intercepts and slope coefficients, for the different levels of data.

\section{Choice modeling results and discussion}

\subsection{Definition of the model and preliminary findings}

This section reports the main results coming out from the multilevel analysis modeling users' perceptions towards toll roads. Before showing the estimates calculated through the binomial logit specification described in Section 4, some preliminary findings for certain explanatory variables, particularly categorical ones, are presented in Table 2. Concerning the whole sample, the majority of respondents $(52.4 \%)$ were positive towards financing the provision of road infrastructure through a toll mechanism. Although at first glance this attitude seems to be fairly homogeneous throughout certain subsamples, noteworthy differences can be identified in some cases, especially when we disaggregate the results by region.

With regard to individual characteristics, we observe that users' perceptions do not vary too much depending on gender. Positive attitudes towards toll roads for men (52.5\%) are only slightly higher when compared to women (52.2\%). The same distribution is also found in the sample concerning trip frequency of use, with a slightly more positive perception for frequent users.

Furthermore, toll road acceptance seems to increase to some extent with age, if we exclude respondents under 24 . The survey shows that
$49.4 \%$ of users between 24 and 34 consider that tolling is an adequate mechanism to finance the provision of roads, while this percentage increases up to $59.9 \%$ for respondents aged above 64 . It can also be found that, the higher the income (particularly above 50,000 Euro), the more positive the users' attitudes towards toll roads. This finding is in line with other previous results referred to in the literature (Odeck and Kjerkreit, 2010).

Table 2

Users' perceptions towards toll roads. Preliminary results in percentage for categorical variables.

\begin{tabular}{|c|c|c|c|}
\hline \multirow[t]{3}{*}{ Level of data } & \multirow[b]{3}{*}{ Explanatory variables } & \multirow{2}{*}{\multicolumn{2}{|c|}{$\begin{array}{l}\text { Dependent variable } \\
\text { Perception towards } \\
\text { toll roads (\%) }\end{array}$}} \\
\hline & & & \\
\hline & & \multirow{2}{*}{$\frac{\text { Positive }}{52.4}$} & \multirow{2}{*}{$\begin{array}{l}\text { Negative } \\
47.6\end{array}$} \\
\hline Total sample & & & \\
\hline \multirow[t]{30}{*}{ Individual } & Gender & & \\
\hline & Men & 52.5 & 47.5 \\
\hline & Women & 52.2 & 47.8 \\
\hline & Age & & \\
\hline & Under 24 & 54.7 & 45.3 \\
\hline & From 24 to 34 & 49.4 & 50.6 \\
\hline & From 35 to 49 & 50.7 & 49.3 \\
\hline & From 50 to 64 & 53.9 & 46.1 \\
\hline & Above 64 & 59.9 & 40.1 \\
\hline & Type of vehicle & & \\
\hline & Car & 53.5 & 46.5 \\
\hline & Light van & 45.9 & 54.1 \\
\hline & Truck & 49.0 & 51.0 \\
\hline & Moto & 81.8 & 18.2 \\
\hline & Bus & 40.0 & 60.0 \\
\hline & Income & & \\
\hline & Below 20,000 Euro & 51.2 & 48.8 \\
\hline & From 20,000 to 30,000 Euro & 52.9 & 47.1 \\
\hline & From 30,000 to 50,000 Euro & 56.1 & 43.9 \\
\hline & Above 50,000 Euro & 60.7 & 39.3 \\
\hline & Not responding & 51.6 & 48.4 \\
\hline & Frequent & 52.5 & 47.5 \\
\hline & Frequency/Type of user & & \\
\hline & Occasional & 52.2 & 47.8 \\
\hline & Trip purpose & & \\
\hline & Commuting & 49.8 & 50.2 \\
\hline & Business & 55.3 & 44.7 \\
\hline & Weekend leisure & 54.6 & 45.4 \\
\hline & Holiday leisure & 52.6 & 47.4 \\
\hline & Other & 50.8 & 49.2 \\
\hline \multirow[t]{6}{*}{ Road infrastructure } & Type of tolled infrastructure & & \\
\hline & Interurban road & 52.2 & 47.8 \\
\hline & Tunnel & 61.6 & 38.4 \\
\hline & Quality alternative & & \\
\hline & Conventional road & 49.8 & 50.2 \\
\hline & Highway & 63.4 & 36.6 \\
\hline \multirow[t]{5}{*}{ Region } & Catalonia & 39.6 & 60.4 \\
\hline & Madrid & 65.5 & 34.5 \\
\hline & Valencia & 47.7 & 52.3 \\
\hline & Basque Country & 54.9 & 45.1 \\
\hline & Galicia & 54.7 & 45.3 \\
\hline
\end{tabular}


If we focus on the influence of road infrastructure characteristics, some heterogeneity on users' attitudes can be noticed depending on the quality of the alternative road. Drivers are significantly more positive towards toll roads (63.4\%) when the free parallel road happens to be a high capacity road. This contrasts with a lower support (49.8\%) in the case that the competing road was of low quality. These results may reflect that the absence of high quality free alternatives forces drivers, in a certain way, to use toll roads to save travel time thus influencing their attitudes towards tolling.

Some heterogeneity is also observed regarding users' attitudes when we analyze the results by region. As can be seen, users' acceptability in Catalonia is low (39.6\%), while in Madrid is relatively high (65.1\%). Other regions such as the Basque Country or Galicia show a more moderate position, with positive attitudes being around 55\%. The asymmetrical density of toll roads throughout the nation might be one of the reasons explaining regional differences because it causes a perceived sentiment of unfairness. In fact, only $14.9 \%$ of the high capacity network is tolled in Madrid, while this percentage is significantly higher in other regions surveyed, such as the Basque Country (41.2\%) and specially Catalonia (47.2\%).

In order to check the validity of these preliminary findings, a multilevel logit specification has been calibrated. The model estimates the probability of being positive towards toll roads-that is, to consider tolls as an appropriate way to finance the provision of roads-and measures the influence of different explanatory variables on this attitude. As pointed out above, the multilevel specification is a suitable econometric technique for exploring regional and inter-road differences from the sample.

Before setting up the multilevel model, some tests for checking multicollinearity between the explanatory variables were applied. The analysis showed that the regional parameters nationalist/regionalist feelings and abundance of toll roads (see Table 1) were highly correlated and thus statistically not independent of each other (correlation coefficient $=0.98$ ). Despite the fact that these variables refer to very different aspects, such a high multicollinearity level does not make possible to separate the partial effect of each explanatory parameter (Gujarati and Porter, 2004) and thus one of them needs to be removed from the model. Given its expected greater influence to explain regional differences in users' perceptions, we opted for keeping the abundance of toll roads within a region as an explanatory variable in the model.

Following the usual procedure for exploring regional differences through a multilevel specification, we developed a stepwise analysis. Firstly, a so-called Model 0 or "empty model" was run to test whether random variation across regions (level 3 ) and toll roads (level 2) are a significant part of the total variation between responses. After that, subsequent models were generated by gradually incorporating explanatory variables concerning individual characteristics (level 1), road infrastructure attributes (level 2) and regional parameters (level 3). Throughout this process, random variation across groups (regions and toll roads) was tested not only for intercepts but also for slope coefficients. In order to make the paper more concise, only results from the initial

Table 3

Users' perceptions towards interurban toll roads: estimation results. Model 0.

\begin{tabular}{|c|c|c|c|c|c|c|}
\hline \multirow{2}{*}{$\frac{\text { Model }}{\text { Variables }}$} & \multicolumn{3}{|l|}{ Model 0.A } & \multicolumn{3}{|l|}{ Model 0.B } \\
\hline & Coeff. & $\begin{array}{l}\text { Std. } \\
\text { error }\end{array}$ & $p$-value & Coeff. & $\begin{array}{l}\text { Std. } \\
\text { error }\end{array}$ & $p$-value \\
\hline \multicolumn{7}{|l|}{ Fixed effects } \\
\hline \multicolumn{7}{|c|}{ Random effects } \\
\hline Toll road & 0.137 & 0.083 & 0.099 & & & \\
\hline Region & 0.346 & 0.119 & 0.004 & 0.341 & 0.115 & 0.003 \\
\hline $\begin{array}{l}-2 \log \\
\text { likelihood }\end{array}$ & -1883.20 & & & -1884.28 & & \\
\hline \multicolumn{3}{|c|}{$\begin{array}{l}\text { Likelihood-ratio test } \\
(0 . B \text { nested in } 0 . A)\end{array}$} & \multicolumn{4}{|c|}{ Prob $>$ chi $^{2}=0.145$} \\
\hline
\end{tabular}

and final models are displayed in the paper. The intermediate results produced (Models I and II) can be checked in the Appendix section.

Table 3 includes different estimates for the zero model. Firstly, Model 0.A allows random intercepts for both the regional and toll road level. As can be seen, the standard deviation of random intercepts for regions is highly significant ( $p$-value $=0.004$ ), while no significant toll road group effect is found in the sample ( $p$-value $>0.05)$. In order to check the statistical significance of the toll road level, we estimated an alternative Model 0.B, only including random effects across regions. By testing the hypothesis of Model 0.B being nested in Model 0.A, differences between likelihood ratios resulted not significant ( $p$-value $=$ 0.145 ). Therefore, there is no evidence of statistically significant disparities among users from different toll roads. In line with Murillo (2008) and Train (2003), we decided to remove random coefficients related to the toll road level $\left(\mathrm{u}_{\mathrm{jk}}\right)$ from the model, and continue the analysis from now on under the assumption of users' differences with a twolevel specification. These authors point out that low or non-significant random effects evidence that groups are not internally homogeneous, so the grouping act has no consequences on the results and observations can thus be considered independent in this case. Random coefficients at the toll road level are then removed in order to avoid false complexity in the model, not supported by the data.

Next, the different explanatory variables were incorporated to the multilevel model, generating Models I to III as set in Section 4. Estimation results from Model III-including all the explanatory variables considered in the research-are displayed in Table 4, and discussed below sorted by the type of explanatory parameter: individual, road-related and regional. Estimation results from the intermediate models generated (Models I and II) are shown in Appendix 4.

\subsection{Analysis of individual characteristics and road infrastructure attributes}

The influence of individual characteristics and road infrastructure attributes on users' perceptions was gradually incorporated in the analysis through Models I and II respectively (see Appendix 4 for more details). Given the small variability of results during the stepwise modeling process, we display the empirical results for the final multilevel specification in Table 4.

Estimates for Model III confirm the relatively low influence of individual socioeconomic characteristics on acceptability towards road charging, as sometimes identified in the literature (Schade and Schlag, 2000; Rienstra et al., 1999). Despite a less positive perception towards toll roads observed in the case of women, no statistically significant differences are found throughout the categories established in terms of age, income or type of vehicle.

We can observe that users' perception becomes less negative as the age increases, but the relationship is not statistically significant ( $p$-value $>0.05$ ) for any of the intervals established. Frequency of trips does neither have an impact on users' perceptions towards toll roads, even though a lower acceptability, not statistically significant, can be observed for occasional users. Concerning the type of vehicle, no statistically different attitudes are found between e.g. truck and car drivers, despite the distinct effect that tolls may have in the generalized cost for each case. Nevertheless, the type of vehicle revealed to be overall a significant variable to explain users' attitudes towards toll roads, at the light of the results for the LR-test.

A more supportive attitude towards toll roads is found for higher income levels, but again a statistically significant influence cannot be concluded from this analysis, as in Odeck and Brathen (2008)or Bhatt et al. (2008), among others. With regard to trip purpose, almost statistical differences are identified for business trips when compared to the base case (commuting). This more positive perception may be caused by the fact that, in some occasions, it is not the employee but the employer who pays for the toll in this type of trips. Furthermore, the LRtest indicates that trip purpose is overall an explanatory variable statistically significant to explain users' attitudes towards toll roads. 
Table 4

Users' perceptions towards interurban toll roads: estimation results. Model III (including individual, toll road and regional parameters).

\begin{tabular}{|c|c|c|c|c|c|}
\hline \multirow[t]{4}{*}{ Level of data } & \multirow[t]{2}{*}{ Explanatory parameters } & \multicolumn{3}{|c|}{ Modeling estimates } & \multirow{4}{*}{$\frac{\text { Overall significance (LR test) }}{p \text {-Value }}$} \\
\hline & & Coeff. & Std. error & $p$-Value & \\
\hline & \multicolumn{4}{|l|}{ Fixed effects } & \\
\hline & Intercept & -4.297 & 0.881 & 0.000 & \\
\hline \multirow[t]{23}{*}{ Individual } & Gender (base reference: male) & & & & 0.001 \\
\hline & Female & -0.279 & 0.085 & 0.001 & \\
\hline & Age (base eference: under 24) & & & & 0.197 \\
\hline & From 24 to 34 & -0.249 & 0.219 & 0.255 & \\
\hline & From 35 to 49 & -0.178 & 0.207 & 0.391 & \\
\hline & From 50 to 64 & -0.013 & 0.214 & 0.952 & \\
\hline & Above 64 & 0.176 & 0.277 & 0.525 & \\
\hline & Type of vehicle (base reference: car) & & & & 0.011 \\
\hline & Light van & -0.251 & 0.153 & 0.101 & \\
\hline & Truck & -0.137 & 0.221 & 0.537 & \\
\hline & Moto & 1.494 & 6.486 & 0.982 & \\
\hline & Bus & -0.767 & 0.664 & 0.248 & \\
\hline & Income (base reference: under $20,000 €$ ) & & & & 0.317 \\
\hline & From 20,000 to $30,000 €$ & 0.080 & 0.131 & 0.541 & \\
\hline & From 30,000 to $50,000 €$ & 0.146 & 0.169 & 0.388 & \\
\hline & Above $50,000 €$ & 0.235 & 0.299 & 0.431 & \\
\hline & Frequency (base reference: frequent user) & & & & 0.476 \\
\hline & Occasional user & -0.066 & 0.092 & 0.476 & \\
\hline & Trip purpose (base reference: commuting) & & & & 0.008 \\
\hline & Business & 0.266 & 0.136 & 0.051 & \\
\hline & Weekend leisure & 0.162 & 0.110 & 0.140 & \\
\hline & Holiday leisure & 0.087 & 0.122 & 0.476 & \\
\hline & Other & -0.049 & 0.146 & 0.739 & \\
\hline \multirow[t]{5}{*}{ Toll road } & $\begin{array}{l}\text { Type of tolled infrastructure } \\
\text { (base reference: road) }\end{array}$ & & & & 0.061 \\
\hline & Tunnel & 0.429 & 0.229 & 0.061 & \\
\hline & Toll rate & -1.481 & 0.985 & 0.133 & 0.133 \\
\hline & $\begin{array}{l}\text { Quality of the alternative route } \\
\text { (base reference: conventional) }\end{array}$ & & & & 0.029 \\
\hline & Highway & 0.296 & 0.136 & 0.029 & \\
\hline \multirow[t]{6}{*}{ Region } & Regional GDP per capita & 0.049 & 0.010 & 0.000 & 0.000 \\
\hline & \% Left-wing parties & -0.081 & 0.015 & 0.000 & 0.000 \\
\hline & $\%$ High capacity roads tolled & -0.012 & 0.004 & 0.008 & 0.008 \\
\hline & Random effects & & & & \\
\hline & Region & 1.77 e-06 & 0.040 & 0.999 & \\
\hline & $-2 \log$ likelihood & -1847.04 & & & \\
\hline
\end{tabular}

Despite the fact that many of the individual explanatory variables included in the model were not statistically significant, a likelihood-ratio test does not reject the hypothesis of Model 0 being nested in Model I (see Appendix 4). Therefore, a statistically significant improvement in the fitting of the model was achieved when including individual characteristics as explanatory variables. Additionally, we can observe that the standard deviation of random intercepts for regions remains significant but in the same order of magnitude when compared to Model 0 . This fact evidences that, from a practical point of view, individual characteristics do not contribute to explain unobserved differences on users' perceptions across regions. This issue will be further explored by testing not only the potential influence of individual characteristics on random intercepts, but also coefficient variations across regions (see comments regarding Appendix 5 below).

Regarding the influence of road infrastructure attributes on users' perceptions, some trends can be identified from the estimates displayed in Table 4. As pointed out by Smirti et al. (2007), the role of contextspecific parameters on users' perceptions seems to be of greater importance than the characteristics of individuals. Regarding the type of toll infrastructure, we can observe that setting tolls in specific spots such as tunnels have for users a higher acceptability than regular interurban roads. According to the estimation results, odds ratio in favor of being positive towards toll roads increases by $53.6 \%$ for users of tunnel facilities. This result, very close to be statistically significant, may be due to the shorter length and consequently smaller toll payments associated to this type of road infrastructure.
As it is expected the level of the toll rate has a negative influence on users' perceptions towards toll roads. Despite not being statistically significant, those users driving in more expensive toll roads have a lower acceptability towards road pricing. Finally, the quality of the alternative free route represents a highly significant parameter to explain users' perceptions, in line with Smirti et al. (2007). We can observe that drivers are $34.4 \%$ more supportive of being charged in toll roads competing with free highways than in toll roads competing with low quality alternatives. This finding seems reasonable given the fact that, when the alternative is not so good, users are more captive to use toll roads.

Again, a likelihood-ratio test confirms the statistically significant improvement ( $p$-value $<0.05$ ) reached in the model after the inclusion of infrastructure-specific characteristics (see Appendix 4). On the other hand, the standard deviation of the random intercepts for regions remains still significant but lower when compared to Model I. Consequently, we can see that road infrastructure attributes contribute to reduce unobserved regional differences on users' acceptability, mainly by taking into account the current heterogeneity across regions in terms of quality of the alternative free road (see Appendix 2). As pointed out above, in regions such as Catalonia or the Basque Country the alternative route is generally a conventional (two-lane) road, while in Madrid tolled sections competing with free highways are more numerous.

With the aim to further explore regional differences for the explanatory variables already considered (individual characteristics and infrastructure attributes), we conducted several supplementary models 
allowing random slopes on predictors. The main results obtained, shown in Appendix 5, make clear that no coefficient variability across regions is present in our sample. Regarding individual characteristics, gender, age or income coefficients do not significantly vary across regions, given the high $p$-value obtained in all cases for both the standard deviation of random slopes and the likelihood-ratio test. Similarly, the analysis does not suggest any regional variation in the slope coefficients concerning infrastructure attributes, such as quality of the alternative route or the toll rate charged.

\subsection{Analysis of regional parameters}

Finally, estimation results are discussed for the three explanatory variables included at the regional level concerning political beliefs, share of toll roads and average wealth. We should point out again that, due to multicollinearity problems, it was not possible to incorporate the variable related to nationalist/regionalist feelings (measured through the vote to nationalist/regionalists parties) in each territory.

As can be seen in Table 4, despite being statistically significant, the wealth of each region measured through the GDP per capita has very limited influence on users' perceptions. According to the results, for a 100 Euro-increase in the regional GDP per capita, the odds ratio in favor of being positive towards tolling increases by only $0.5 \%$, so toll acceptability remains quite similar for different levels of regional wealth. This is also in line with the results we obtained regarding the influence of the individual level of income on users' attitudes. Therefore, the average standard of living within a region seems to play a minor role on toll roads acceptability, at least for the case of Spain. These results contrast with findings in other areas such as health services (Karlsdotter et al., 2009).

Attitudes towards toll roads are however more noticeably affected by the political atmosphere within the region. This result confirms the conclusions by Hårsman and Quigley (2010) regarding the influence of political bias on road charging acceptability. Given the negative sign of the coefficient in the model, an increase in the vote to left-wing parties at the regional level reduces the support for toll roads. This finding makes sense, since Spanish socialist and communist parties promote a greater involvement of the government in the economy, typically associated in Spain to publicly-funded services. This attitude is then politically opposed to paying a toll for using roads. We can also note that this conclusion deserves to be complemented with an analysis of the influence of political beliefs at the individual level.

Additionally, as might be expected the density of toll roads within a region significantly influences users' perceptions towards toll roads. Even excluding the influence of infrastructure attributes-such as the quality of the alternative road in each case-or political beliefs, we can observe that users from regions with a higher density of toll roads have a more negative attitude towards road charging. This fact may be explained by the marked asymmetry of toll roads across regions, which is strongly connected to the influence of perceived fairness on pricing acceptability, as pointed out by Cools et al. (2011). In this respect, it is not strange that users from Catalonia or Valencia, very frequently obliged to pay for using high capacity roads, feel unfairly treated when compared to other regions with a more extensive free high-capacity road network.

We also find that the inclusion of regional parameters significantly improve the fitting of the model, given the results obtained for the likelihood-ratio test ( $p$-value $<0.05$ ). It is also worth noticing how unobserved effects across regions almost disappear in Model III. As can be seen in Table 4, random coefficients become very close to zero and non-statistically significant after including regional parameters in the model. Then, we may conclude that regional differences initially identified on users' attitudes towards toll roads can be appropriately explained by the variables already included in the model. Finally, Table 5 refines the results by removing overall non-significant explanatory variables such as age or income, with no effect on the fitting of the model according to the likelihood-ratio test.
Table 5

Users' perceptions towards interurban toll roads: refining results.

\begin{tabular}{|c|c|c|c|c|}
\hline \multirow{4}{*}{$\begin{array}{l}\text { Level of } \\
\text { data }\end{array}$} & \multirow{3}{*}{$\begin{array}{l}\text { Explanatory parameters } \\
\text { Fixed effects }\end{array}$} & \multicolumn{3}{|c|}{ Modeling estimates } \\
\hline & & Coeff. & \multirow[t]{2}{*}{$\begin{array}{l}\text { Std. } \\
\text { error }\end{array}$} & \multirow[t]{2}{*}{$p$-Value } \\
\hline & & \multirow[b]{2}{*}{-4.441} & & \\
\hline & Intercept & & 0.863 & 0.000 \\
\hline \multirow[t]{12}{*}{ Individual } & Gender (base reference: male) & & & \\
\hline & Female & -0.306 & 0.081 & 0.000 \\
\hline & $\begin{array}{l}\text { Type of vehicle (base reference: } \\
\text { car) }\end{array}$ & & & \\
\hline & Light van & -0.276 & 0.152 & 0.070 \\
\hline & Truck & -0.146 & 0.221 & 0.510 \\
\hline & Moto & 1.981 & 15.692 & 0.990 \\
\hline & Bus & -0.714 & 0.666 & 0.283 \\
\hline & $\begin{array}{l}\text { Trip purpose (base reference: } \\
\text { commuting) }\end{array}$ & & & \\
\hline & Business & 0.257 & 0.135 & 0.057 \\
\hline & Weekend leisure & 0.196 & 0.105 & 0.062 \\
\hline & Holiday leisure & 0.144 & 0.115 & 0.211 \\
\hline & Other & 0.044 & 0.137 & 0.747 \\
\hline \multirow[t]{5}{*}{ Toll road } & $\begin{array}{l}\text { Type of tolled infrastructure (base } \\
\text { reference: road) }\end{array}$ & & & \\
\hline & Tunnel & 0.437 & 0.228 & 0.056 \\
\hline & Toll rate & -1.486 & 0.983 & 0.130 \\
\hline & $\begin{array}{l}\text { Quality of the alternative route } \\
\text { (base reference: conventional) }\end{array}$ & & & \\
\hline & Highway & 0.299 & 0.135 & 0.027 \\
\hline \multirow[t]{5}{*}{ Region } & Regional GDP per capita & 0.048 & 0.010 & 0.000 \\
\hline & \% Left-wing parties & -0.082 & 0.015 & 0.000 \\
\hline & $\begin{array}{l}\text { \% High capacity roads tolled } \\
\text { Random effects }\end{array}$ & -0.011 & 0.004 & 0.011 \\
\hline & Region & $1.68 \mathrm{e}-05$ & 0.039 & 0.999 \\
\hline & -2 log likelihood & -1851.61 & & \\
\hline
\end{tabular}

\subsection{Discussion of the results}

In this subsection, we briefly discuss the results obtained in this research work with regard to unobserved differences at the regional level. To that end, we included in Fig. 2 the evolution of random intercepts for the main models calibrated stepwise in this paper (Models 0 to III). At first glance, some trends can be identified concerning users' differences across regions. Random intercepts in Model 0 evidence that users from Valencia, and especially from Catalonia, show a more negative perception towards toll roads than the average. This contrasts with regions such as Galicia or the Basque Country, in an intermediate position, and especially with the case of Madrid, whose users shows a higher positive attitude towards road charging.

As mentioned above, this view can be explained in the light of the asymmetrical tolling conditions currently applied, resulting from a changing national road transport policy over time. This fact has caused a marked regional heterogeneity that in its turn has provoked a negative perception due to a sentiment of unfairness in the regions more widely affected by tolls. This situation, combined with political beliefs and different tolling infrastructure attributes across regions, has created a significant anti-toll atmosphere in certain parts of the country, although they were initially favored by the early implementation of toll roads.

The lack of change in random intercepts observed between Models 0 and I (see Fig. 1) evidences the limited influence of the characteristics of individuals on regional differences. Additionally, infrastructure attributes only seem to be of great importance for the case of Madrid, given that its random coefficient goes down from 0.52 to 0.33 . This fact appears to be strongly connected with the fact that toll roads in this region usually have a free high-capacity alternative (see Appendix 2 ). Finally, we can see that undoubtedly differences across regions are more affected by regional context-specific parameters included in the model, especially the abundance of toll roads. In this respect, a more 


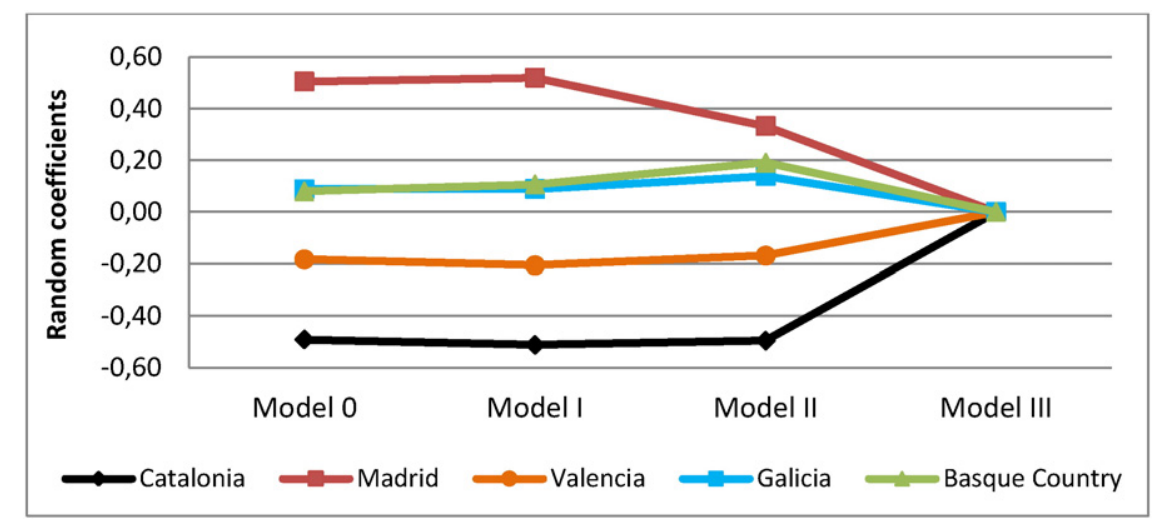

Fig. 2. Evolution of random effects regarding region intercepts for the different models calibrated.

coordinated tolling policy would be desirable to eliminate, or at least to reduce, these regional differences and sentiments of unfairness present in certain territories.

\section{Conclusions and further research}

The multilevel logit model developed in this research enabled us to explore and quantify the explanatory effect of context-specific variables, not only at the regional level but also concerning road-related attributes. From the analysis we were able to obtain some interesting conclusions.

The first conclusion is that users' perceptions towards toll roads may experience substantial differences across regions within the same nation. This seems to be especially crucial in those cases undergoing a heterogeneous toll implementation process across territories.

The second conclusion is that regional differences on tolling acceptability seem to be more affected by context-specific variables, related to either toll road or regional characteristics, than by the attributes of individuals. Particularly, those regions comparatively having a higher share of toll roads or more burdensome tolling infrastructure generally show a more negative perception towards road charging. This idea provides useful insight for future research, given the fact that these types of variables have barely been modeled till now.

The third conclusion concerns the consequences of developing an asymmetrical road transport policy across regions. In parallel with the promotion of regional development and the analysis of territorial equity, a more coordinated implementation of road transport policies across regions seems to be advisable in order to avoid the sentiments of being treated unfairly that some territories perceive. Then, a more balanced national implementation of pricing strategies and road accessibility provision can contribute to better distribute the burden of road financing, as well as to avoid negative perceptions in certain territories.

From the results of this paper, some aspects can be pointed out for further research. First, further efforts are needed to extend the current analysis to regions with a lower presence of toll roads, in order to estimate the potential consequences and acceptability of establishing a more homogeneous road transport policy throughout the nation. Additionally, a trans-national research would be highly desirable, especially at the European level, with the aim to evaluate public perceptions towards the current EU charging policy. Finally, the influence of further explanatory variables on users' perceptions needs to be explored more deeply, likely by incorporating political beliefs at the individual level or latent variables through a structural equation approach.

\section{Acknowledgement}

The authors wish to thank the Spanish Ministry of Economy and Competitiveness (MINECO), which has funded the project "EU Support Mechanisms to promote Public Private Partnerships for financing TransEuropean Transport Infrastructure" [TRA 2012-36590].

\section{Appendix 1. Variables measured and questions addressed in the survey}

\begin{tabular}{|c|c|c|}
\hline Variable & Question addressed & Options provided \\
\hline \multicolumn{3}{|l|}{ Socioeconomic characteristics } \\
\hline Gender & & Male; female \\
\hline Age & Where do you place your age in the following intervals? & Under 25 ; from 25 to 34 ; from 35 to 49 ; from 50 to 64 ; above 64 \\
\hline Income & $\begin{array}{l}\text { Where do you put your personal income in the following } \\
\text { intervals? }\end{array}$ & Under 20,000; From 20,000 to 30,000; From 30,000 to 50,000; Above 50,000 \\
\hline Type of vehicle & & Car; light van; truck; moto; bus \\
\hline Region & & Catalonia; Madrid; Valencia; Basque Country; Galicia \\
\hline Frequency/type of user & $\begin{array}{l}\text { How often do you use toll roads, considering the following } \\
\text { intervals? }\end{array}$ & $\begin{array}{l}>8 \text { trips per month (frequent user); }<8 \text { trips per month (occasional user); } \\
\text { Never used it before (potential user) }\end{array}$ \\
\hline $\begin{array}{l}\text { Trip purpose (only for frequent } \\
\text { and occasional users) }\end{array}$ & $\begin{array}{l}\text { What is the most common trip purpose when you use toll } \\
\text { roads? }\end{array}$ & $\begin{array}{l}\text { Commuting; business/work related activities; weekend leisure; holiday } \\
\text { leisure; other }\end{array}$ \\
\hline \multicolumn{3}{|l|}{ Characteristic of the toll road } \\
\hline Quality of the free alternative & & Conventional road; Highway \\
\hline Toll rate & & Expressed in Euro/km \\
\hline Tunnel & & Tunnel; interurban road \\
\hline \multicolumn{3}{|l|}{ Attitudes towards tolls } \\
\hline Perception towards toll roads & $\begin{array}{l}\text { Do you think that tolls are an appropriate mechanism to } \\
\text { finance the provision of roads? }\end{array}$ & Yes; no \\
\hline
\end{tabular}


Appendix 2. Main characteristics of the toll roads included in the sample

\begin{tabular}{|c|c|c|c|c|c|c|c|}
\hline \multirow[t]{2}{*}{ Region } & \multirow[t]{2}{*}{ Toll road } & \multirow[t]{2}{*}{ Year of start } & \multirow[t]{2}{*}{ Length (km) } & \multirow[t]{2}{*}{ Toll rate, light vehicle (Euro/km) } & \multirow[t]{2}{*}{ High capacity alternative road } & \multicolumn{2}{|c|}{ People surveyed } \\
\hline & & & & & & By toll road & By region \\
\hline \multirow[t]{10}{*}{ Catalonia } & Montmeló-La Jonquera & 1972 & 135.6 & 0.089 & Partly (3.0\%) & 58 & 558 \\
\hline & Montmeló-Papiol & 1978 & 26.6 & 0.092 & No & 135 & \\
\hline & Barcelona-Tarragona & 1975 & 96.6 & 0.089 & Partly (9.7\%) & 78 & \\
\hline & Zaragoza-Mediterráneo & 1976 & 215.5 & 0.095 & Partly (6.6\%) & 18 & \\
\hline & Barcelona-Montmeló & 1972 & 14.2 & 0.100 & Yes & 89 & \\
\hline & Montgat-Palafolls & 1969 & 43.1 & 0.087 & No & 67 & \\
\hline & Castelldefels-El Vendrell & 1992 & 56.3 & 0.163 & No & 39 & \\
\hline & San Cugat-Manresa & 1990 & 43.1 & 0.147 & No & 26 & \\
\hline & Vallvidriera Tunnels & 1992 & 16.7 & 0.206 & No & 40 & \\
\hline & Cadí Tunnel & 1986 & 29.7 & 0.392 & No & 8 & \\
\hline \multirow[t]{7}{*}{ Madrid } & Madrid-Guadalajara & 2003 & 64.1 & 0.099 & Yes & 59 & 548 \\
\hline & Madrid-Arganda & 2003 & 33.1 & 0.096 & Yes & 91 & \\
\hline & Madrid-Ocaña & 2003 & 53 & 0.104 & Yes & 59 & \\
\hline & Madrid-Navalcarnero & 2003 & 29 & 0.109 & Yes & 61 & \\
\hline & Eje Aeropuerto & 2005 & 8.8 & 0.143 & Yes & 103 & \\
\hline & Villalba-Adanero & 1977 & 69.6 & 0.144 & No & 162 & \\
\hline & Madrid-Toledo & 2006 & 60 & 0.092 & Yes & 13 & \\
\hline \multirow[t]{4}{*}{ Valencia } & Tarragona-Valencia & 1978 & 225.3 & 0.096 & Partly (19.8\%) & 177 & 562 \\
\hline & Valencia-Alicante & 1976 & 148.5 & 0.097 & Partly $(9.2 \%)$ & 198 & \\
\hline & Circunvalación Alicante & 2007 & 28.5 & 0.101 & Yes & 49 & \\
\hline & Alicante-Cartagena & 2001 & 76.6 & 0.061 & No & 138 & \\
\hline \multirow[t]{5}{*}{ Basque Country } & Artxanda Tunnels & 2003 & 3 & 0.492 & No & 62 & 558 \\
\hline & Bilbao-Ermua & 1976 & 36.2 & 0.087 & Partly (5.3\%) & 162 & \\
\hline & Ermua-Behobia & 1976 & 87.6 & 0.107 & No & 181 & \\
\hline & Maltzaga-Arrasate & 2003 & 35.6 & 0.107 & No & 59 & \\
\hline & Bilbao-Zaragoza & 1978 & 294.4 & 0.092 & Partly (18.0\%) & 94 & \\
\hline \multirow[t]{4}{*}{ Galicia } & Ferrol-Front. Portuguesa & 1979 & 218.9 & 0.089 & Partly (14.4\%) & 264 & 543 \\
\hline & Santiago-Alto Sto. Domingo & 2003 & 56.6 & 0.094 & No & 53 & \\
\hline & La Coruña-Carballo & 1998 & 32.6 & 0.068 & No & 145 & \\
\hline & Puxeiros-Val Miñor & 1999 & 25.2 & 0.060 & No & 81 & \\
\hline
\end{tabular}

Appendix 3. Application of the multilevel specification to the case study adopted

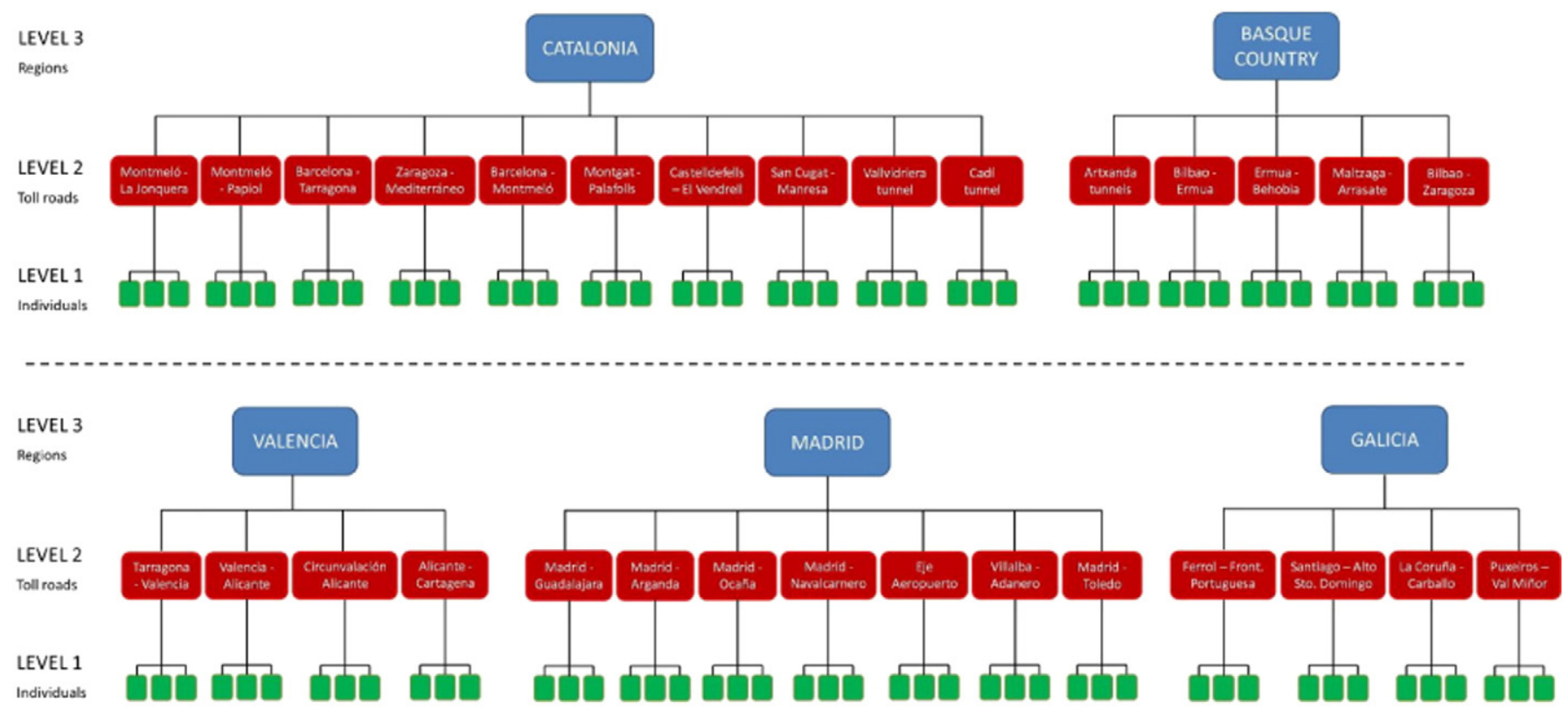


Appendix 4. Users' perceptions towards interurban toll roads: estimation results. Models 0 (lack of explanatory variables), Model I (including individual characteristics) and Model II (including infrastructure attributes)

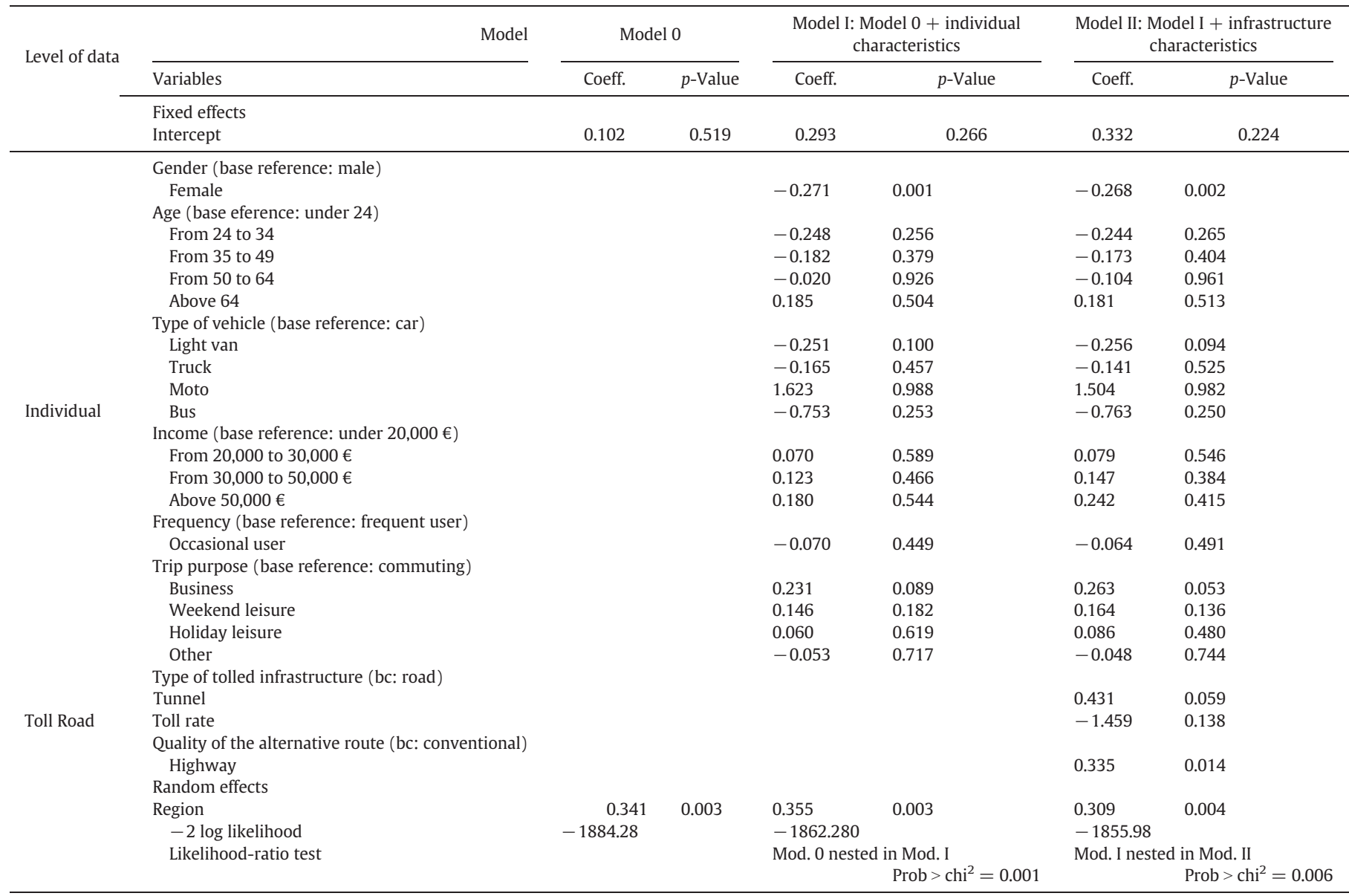

Appendix 5. Users' perceptions towards interurban toll roads: testing regional differences for slope coefficients

\begin{tabular}{|c|c|c|c|c|c|c|}
\hline Model & Assumption & Random coefficient & p-value & $\begin{array}{l}\text { Random region } \\
\text { coefficient }\end{array}$ & Log-likelihood & $\begin{array}{l}\text { Prob. nesting model I > } \\
\text { chi2 }\end{array}$ \\
\hline Model I. Gender & Regional differences on gender coefficients & 0.147 & 0.405 & 0.355 & -1862.16 & 0.176 \\
\hline Model I. Age & Regional differences on age coefficients & 0.000 & 0.999 & 0.355 & -1862.28 & 1.000 \\
\hline Model I. Income & Regional differences on income coefficients & 0.158 & 0.116 & 0.198 & -1861.49 & 0.132 \\
\hline Model & Assumption & Random coefficient & p-value & $\begin{array}{l}\text { Random region } \\
\text { coefficient }\end{array}$ & Log-likelihood & $\begin{array}{l}\text { Prob. nesting model II > } \\
\text { chi2 }\end{array}$ \\
\hline Model II. Alternative & Regional differences on quality of the alternative coefficient & 0.000 & 0.999 & 0.309 & -1855.98 & 0.999 \\
\hline Model II. Toll rate & Regional differences on toll rate coefficient & 0.000 & 0.999 & 0.309 & -1855.98 & 0.999 \\
\hline
\end{tabular}

\section{References}

Abane, A.M., 2011. Travel behavior in Ghana: empirical observations from four metropolitan areas. J. Transp. Geogr. 19, 313-322.

Aitken, V., Bell, S., Hills, S., Rees, L., 2014. Public acceptability of indirect potable water reuse in the south-east of England. Water Sci. Technol. Water Supply 14, 875-885.

Alberts, H., Bowen, J.T., Cidell, J.L., 2009. Missed opportunities: the restructuring of Berlin's Airport System and the city's position in International Airline Networks. Reg. Stud. 43 , 739-758.

Ben-Akiva, M.E., Lerman, S.R., 1995. Discrete Choice Analysis: Theory and Application to Travel Demand. MIT Press, Cambridge, MA.

Bhatt, K., Higgins, T., Berg, J.T., 2008. Lessons learned from international experience in congestion pricing. US Department of Transportation \& Federal Highway Administration.

Castillo-Manzano, J., Fageda, X., 2014. How are investments allocated in a publicly owned port system? Political Factors versus economic criteria. Reg. Stud. 48, 1279-1294.
Condeço-Melhorado, A., Gutiérrez, J., García-Palomares, J.C., 2011. Spatial impacts of road pricing: accessibility, regional spillovers and territorial cohesion. Transp. Res. A 45 185-203.

Cools, M., Brijs, K., Tormans, H., Moons, E., Janssens, D., Wets, G., 2011. The socio-cognitive links between road pricing acceptability and changes in travel-behavior. Transp. Res. A Policy Pract. 45, 779-788.

de Leeuw, J., Meijer, E., 2007. Introduction to multilevel models. In Handbook of Multilevel Analysis. Springer.

Dill, J., Weinstein, A., 2007. How to pay for transportation? A survey of public preferences in California. Transp. Policy 14, 346-356.

Eksler, V., Lassarre, S., Thomas, I., 2008. Regional analysis of road mortality in Europe. Public Health 122 (9), 826-837.

Fujii, S., Gärling, T., Jakobsson, C., Jou, R.C., 2004. A cross-country study of fairness and infringement on freedom as determinants of car owners' acceptance of road pricing. Transportation 31, 285-295. 
Furst, E.W.M., Dieplinger, M., 2014. The acceptability of road pricing in Vienna: the preference patterns of car drivers. Transportation 41 (4), 765-784.

Gaunt, M., Rye, T., Allen, S., 2007. Public acceptability of road user charging: The case of Edinburgh and the 2005 Referendum. Transp. Rev. 27, 85-102.

Gehlert, T., Kramer, C., Nielsen, O.A., Schlag, B., 2011. Socioeconomic differences in public acceptability and car use adaptation towards urban road pricing. Transp. Policy 18 , 685-694.

Goldstein, H., 2003. Multilevel Statistical Models. Institute of Education, Arnold, London.

Gomez, J., Papanikolaou, A., Vassallo, J.M., 2015. Users' perceptions and willingness to pay in interurban toll roads: identifying differences across regions from a nationwide survey in Spain. Transportation. http://dx.doi.org/10.1007/s11116-015-9662-6.

Gujarati, D., Porter, D.C., 2004. Basic Econometrics. fourth ed. The Mc Graw-Hill Companies.

Hårsman, B., Quigley, J.M., 2010. Political and public acceptability of congestion pricing: ideology and self-interest. J. Policy Anal. Manage. 29 (854-U221).

Hox, J., 2002. Multilevel Analysis: Techniques and Applications. Lawrence Erlbaum Associates, Hillsdale, NJ.

Kallbekken, S., Garcia, J.H., Korneliussen, K., 2013. Determinants of public support for transport taxes. Transp. Res. A Policy Pract. 58, 67-78.

Karlsdotter, K., Martín, J.J., López, M.P., Jódar, F., García, L., 2009. Análisis multinivel de la influencia de la renta individual y regional en la salud de los españoles en 2007. Congreso de la Asociación Española de Ciencia Regional. XXXV Reunión de estudios regionales. IV Jornades valencianes d'estudis regionals.

Kockelman, K.M., Podgorski, K.V., Bina, M., Gadda, S., 2009. Public perceptions of pricing existing roads and other transportation policies: the Texas perspective. J. Transp. Res. Forum 48, 19-38.

Koppelman, F.S., Bhat, C., 2006. A self instructing course in mode choice modeling: multinomial and nested logit models. Prepared for the US Department of Transportation, Federal Transit Administration.

Lassarre, S., Thomas, I., 2005. Exploring road mortality in Europe: national versus regiona realities. J. R. Stat. Soc. A. Stat. Soc. 168, 127-144

Marciano, J.A., Lilieholm, R.J., Teisl, M.F., Leahy, J.E., Neupane, B., 2014. Factors affecting public support for forest-based biorefineries: a comparison of mill towns and the general public in Maine, USA. Energ Policy 75, 301-311.

Ministerio de Fomento, 2011a. Informe 2010 sobre el sector de autopistas de peaje en España. Delegación del Gobierno en las Sociedades Concesionarias de Autopistas Nacionales de peaje.

Ministerio de Fomento, 2011b. Anuario Estadístico 2010. Centro de Publicaciones. Secretaría General Técnica.
Murillo, F.J., 2008. Los Modelos Multinivel como herramienta para la investigación educativa. Magis. Revista Internacional de Investigación Educativa Vol. 1, pp. 17-34.

Odeck, J., Brathen, S., 2008. Travel demand elasticities and users attitudes: a case study of Norwegian toll projects. Transp. Res. A 42, 77-94.

Odeck, J., Kjerkreit, A., 2010. Evidence on users' attitudes towards road user charges-a cross sectional survey of six Norwegian toll schemes. Transp. Policy 17, 349-358.

Oosterhaven, J., Eding, G.G., Stelder, D., 2001. Clusters, linkages and interregional spillovers: methodology and policy implications for the two Dutch mainports and the rural North. Reg. Stud. 35, 809-822.

Papadimitriou, E., Theofilatos, A., Yannis, G., Cestac, J., Kraiem, S., 2014. Motorcycle riding under the influence of alcohol: results from the SARTRE-4 survey. Accid. Anal. Prev. 70, 121-130.

Podgorski, K.V., Kockelman, K.M., 2006. Public perceptions of toll roads: a survey of the Texas perspective. Transp. Res. A 40, 888-902.

Rienstra, S.A., Rietveld, P., Verhoef, E.T., 1999. The social support for policy measures in passenger transport. A statistical analysis for The Netherlands. Transp. Res. D 4, $181-200$.

Sandow, E., 2008. Commuting behavior in sparsely populated areas: evidence from northern Sweden. J. Transp. Geogr. 16, 14-27.

Schade, J., Schlag, B., 2000. Acceptability of urban transport pricing. Research Report 72. Government Institute for Economic Research, Helsinki.

Schuitema, G., Steg, L., Forward, S., 2010. Explaining differences in acceptability before and acceptance after the implementation of a congestion charge in Stockholm. Transp. Res. A Policy Pract. 44, 99-109.

Smirti, M., Evans, A., Gougherty, M., Morris, E., 2007. Politics, public opinion and project design in California road pricing. Transp. Res. Rec. 1996, 41-48.

Tolon-Becerra, A., Lastra-Bravo, X., Flores-Parra, I., 2013. National and regional analysis of road accidents in Spain. Traffic Inj. Prev. 14 (5), 486-495.

Train, K., 2003. Discrete Choice Methods With Simulation. Cambridge University Press.

Vassallo, J.M., Ortega, A., Baeza, M.Á., 2012. Impact of the economic recession on toll highway concessions in Spain. J. Manag. Eng. 28, 398-406.

Yusuf, J.E., O'Connell, L., Anuar, K.A., 2014. For whom the tunnel be tolled: a four-factor model for explaining willingness-to-pay tolls. Transp. Res. A 59, 13-21.

Zheng, Z., Zhiyuan, L., Liu, C.L., Shiwakoti, N., 2014. Understanding public response to a congestion charge: a random-effects ordered logit approach. Transp. Res. A Policy Pract. 70, 117-134. 